\title{
The experience of women living with pelvic girdle pain and participation in activity after childbirth
}

Rosie Elkins-Bushnell, Occupational therapist, Lewes and North Wealdon Occupational Therapy Team, East Sussex County Council County, Lewes, England, UK

Paul Boyle, Senior lecturer in occupational therapy, School of Health Sciences, University of Brighton, Eastbourne, England, UK

\section{Abstract}

Background/Aims: Pelvic girdle pain is a musculoskeletal condition associated with pregnancy that can continue long-term after childbirth. There is currently limited information as to how to support women with this condition. The aim of this study was to explore the occupational difficulties that are experienced by women with pelvic girdle pain, and acquire an understanding as to how they participate in activity.

Methods: Five women experiencing pelvic girdle pain after childbirth were recruited purposively through a charity in the United Kingdom. A qualitative study drawing upon hermeneutic theory was conducted using semi-structured interviews. The data was then transcribed and analysed by way of thematic analysis.

Findings: Four themes emerged from the data including: activity affected by pelvic girdle pain; factors restricting participation in activity; factors promoting participation in activity; and the emotional impact of a change in participation.

Conclusions: The study highlights the broad range of activities that are affected by this condition, and the complex interplay between internal and external factors that can impact on participation. The findings may assist health professionals when considering ways of supporting women living with pelvic girdle pain after childbirth.

Key words: Activities of daily living, Mothering, Pelvic girdle pain

\section{Background}

Pelvic girdle pain is a musculoskeletal condition associated with pregnancy that causes pain in and around the pelvis (Vleeming et al, 2008). Pain is experienced between the posterior iliac crest and the gluteal fold, and will often radiate to the pubic symphysis as well as the posterior thigh (Vleeming et al, 2008). Pain limits normal movement and often leads to a reduced capacity to stand, sit and walk (Vleeming et al, 2008). The causes for pelvic girdle pain are many and include mechanical, metabolic, traumatic, hormonal and degenerative factors; it is now increasingly thought to be a combination of these that provides the best explanation (Aldabe et al, 2012). Symptoms typically begin during pregnancy and end with childbirth; however, these symptoms have been found to persist long-term in around 7-10\% of women (Albert et al, 2001; Vleeming et al, 2008; Vermani et al, 2010). 
The prevalence of pelvic girdle pain varies, acccording to Vleeming et al (2008) one in five pregnant women are affected by pelvic girdle pain and there appears to be little awareness of this condition among the general public and within healthcare (Vleeming et al, 2008; Elden et al, 2013). Due to this, together with inconsistent research on outcomes, there are currently few treatment options for pelvic girdle pain in the UK (Kanakaris et al, 2011). Treatment options include bed rest, water gymnastics, physical fitness and pelvic tilt exercises, avoiding maladaptive movements, acupuncture, and supervised physiotherapy (Kanakaris et al, 2011).

The National Institute for Health and Care Excellence (NICE) guidelines on postnatal care currently state that 'Women experiencing backache in the postnatal period should be managed as in the general population' (NICE, 2006), despite widespread recognition that pelvic girdle pain requires specific manual therapy treatment from a specialist physiotherapist, chiropractor or osteopath (Pelvic Obstetric and Gynaecological Physiotherapy, 2015; Fishburn and Cooper, 2015). There is evidence to suggest that women who receive manual therapy to restore symmetry of movement to the pelvic joints experience a reduction in pain and improvement in function (Buyruk et al, 1999; Damen et al, 2001). It appears that many women continue to live with symptoms that substantially impact on their ability to carry out daily activities (Engeset et al, 2014; Pelvic Obstetric and Gynaecological Physiotherapy, 2015).

Occupational therapists generally understand humans as occupational beings who participate in occupations, or daily activities, which are essential for their wellbeing (Yerxa, 1990). Previous studies have highlighted the impact pelvic girdle pain can have on participation in daily activities, such as women not being able to work, carry out household tasks or engage in previously enjoyed leisure pursuits (Elden et al, 2013; Engeset et al, 2014). Women with other pain-related conditions have also experienced occupational issues relating to motherhood, such as not being able to play on the floor or participate in outdoor activities (Poole et al, 2009). Elden et al (2013) concluded that pelvic girdle pain affects activities associated with the role of being a mother, partner and professional.

There is literature that shows that pelvic girdle pain impacts on women's daily lives at home and the workplace in a profound way (Elden et al, 2013; Persson et al, 2013; Engeset et al 2014; Wuytack et al, 2015a). Persson et al (2013) carried out a grounded theory study in Sweden highlighting that women worried the pain would never go away and that they were not being a proper mother. In another study, Engeset et al (2014) carried out phenomenological research in Norway highlighting how exhaustion can be a factor resulting in missed hobbies and social activities. These studies and others, as suggested by Mackenzie et al (2018), provide strong reasoning for the recognition of pelvic girdle pain as a serious health issue. Mackenzie et al (2018) raise the important point of safety regarding the carrying and controlling of children, which is an important consideration for practitioners working with this client group.

It appears that symptoms lasting up to 2 years after childbirth is common, however there is little information relating to the lifelong effects of pelvic girdle pain, despite women reporting symptoms up to 22 years post-delivery (Engeset et al, 2014). Wuytack et al (2015a) concluded that understanding the long-term effects of pelvic girdle pain on daily life, and acknowledging women's experiences of this phenomenon could lead to improved care and rehabilitation.

The motivation behind the current study was the authors' interest in safety and wellbeing and to add to the growing body of literature in this area from an occupational therapy perspective in the UK, where practitioners often work in the home. The aim of this study therefore was to explore the occupational difficulties that are experienced by women with pelvic girdle pain after childbirth, and acquire an understanding as to how they have adapted to participate in activity. 


\section{Methods}

A constructivist ontological and interpretivist epistemological position guided the study, as it was the authors' view that participants were likely to have different realities and individual experiences of what it meant to live with pelvic girdle pain and that previous knowledge and experience was likely to influence participants' perceptions of their lives (Crotty, 1998). Influenced by hermeneutics according to McCaffrey et al (2012), this approach was chosen to explore the viewpoints of women with pelvic girdle pain, as this allowed for the interpretation of their everyday experiences.

\section{Recruitment}

Purposive sampling was used to recruit five women through a national charity in the UK that supports women with pelvic girdle pain [AQ: what is the name of the charity?]. This form of sampling is considered appropriate in qualitative studies in order to recruit participants who have experience of the phenomenon under investigation (Crotty, 1998). A recruitment poster was placed on the charity's website and as a link on their social media page. Women were invited to contact the first author to express interest and a participant information sheet was then dispatched. For convenience, potential participants were offered one-to-one interviews either by a face-to-face meeting at the university or through Skype if they preferred. [AQ: did they sign any consent forms?]

Participants were required to have a diagnosis of, or be receiving treatment for, pelvic girdle pain, and experiencing current symptoms. Exclusion criteria were women who were pregnant or had a baby in the last 6 weeks; and those experiencing any other significant health condition that affected daily activities. There was no set criteria as to how many weeks postpartum participants were required to be.

A total of 25 women requested information and 7 met the criteria. The 5 participants who took part were the first to agree interview appointments and all provided signed consent forms. Finlay (2011) suggests sample sizes in this region are in-keeping with studies that focus on exploration of a phenomenon rather than providing findings that can be generalised. A summary of the participants details are provided below in Table 1.

Table 1: Summary of details of the participants

\begin{tabular}{|c|c|c|c|c|}
\hline Participant & Age & Age of children & Relationship & $\begin{array}{c}\text { Employment } \\
\text { status }\end{array}$ \\
\hline 1 & 34 & 12,6 and 2 & Married & $\begin{array}{c}\text { Administrator } \\
\text { (working from } \\
\text { home) and } \\
\text { student }\end{array}$ \\
\hline 2 & 46 & 9 & Married & $\begin{array}{c}\text { Administrator } \\
\text { (working from } \\
\text { home) }\end{array}$ \\
\hline 3 & 32 & 10 and 2 & Married & $\begin{array}{c}\text { Charity worker } \\
\text { (working from } \\
\text { home) }\end{array}$ \\
\hline 4 & 32 & 6 and 3 & Cohabiting & Teacher \\
\hline 5 & 44 & 5 and 1 & Single & $\begin{array}{c}\text { Not in paid } \\
\text { employment }\end{array}$ \\
\hline
\end{tabular}




\section{Data collection}

The first author carried out a pilot interview with a postgraduate occupational therapy student, which helped to develop an interview guide. This was then used to facilitate semi-structured interviews allowing for opening questions, transition questions, key questions and closing questions, as well as additional probing questions in order to achieve depth and detail, while at the same time keeping an open mind and encouraging discussion (Brinkmann and Kvale, 2015). Interviews lasted 30-75 minutes and were audio-recorded. Two interviews were face-to-face and three were conducted using Skype.

\section{Ethical approval}

Ethical approval was granted from the University of Brighton (SREGP 27/11/15). Those attending face-to-face appointments read and signed a consent form before the interview. For the Skype interviews consent forms were posted and returned before the interview.

\section{Data analysis}

The interviews were transcribed verbatim by the first author who also carried out thematic analysis as outlined by Braun and Clarke (2006). This involved listening initially to the recordings, then transcribing, then reading closely to identify meaning units, codes and themes, which were then discussed and reviewed with the second author. Like Gadamer (1989), the authors took the position that all human relationships involve some form of interpretation, which in turn is influenced by background and language including culture and gender. This position therefore assumed that human perception comes from the interaction between subject and object and interpretation of these (Finlay and Ballinger, 2006). Therefore, analysis of the data to understand the experience of the participants, as suggested by Finlay (2011), required close listening and respect for the participants' interpretation of their world, and this point was central in relation to the interpretation of the data by the authors.

The authors endeavoured to adhere to hermeneutic theory. In this way, a small sample size was decided upon, which allowed for detailed and nuanced depth rather than quantity, while simultaneously generating sufficient data that might assist others to replicate the study (Fusch and Ness, 2015). Member checking was not used as this would allow participants to reflect on their comments, instead the researchers endeavoured to use a reflexive approach throughout to account for their interpretation of the data as suggested by Finlay (2011). Reflexivity is important in order to recognise the position of the researcher in order to enhance credibility by avoiding bias (Clancy, 2013). The authors did not subscribe to the idea of complete neutrality but instead formalised personal reflexivity to become active inquirers in the study. To facilitate interpretation and analysis of the data, a detailed reflexive diary was kept by the first author to record her developing beliefs and assumptions in order to recognise her own experience of being a mother living with this condition. This in turn was then discussed with the second author who, although had pain management experience, had little experience of this particular condition.

\section{Findings}

Four themes emerged from the data:

- Activity affected by pelvic girdle pain

- Factors restricting participation in activity

- Factors promoting participation in activity

- The emotional impact of a change in participation. 


\section{Activity affected by pelvic girdle pain}

This theme emerged through the women talking about how they experience activities of daily living with pelvic girdle pain. Activities associated with mothering were prominent, and participants felt that interactions with their children had changed as a result of their condition. Most felt as though they missed out on active or outdoor play, such as going cycling or to the park, which in some cases other family members continued to do. Getting down to the floor to play with their child was often considered as impossible for some because of pain. All of the women reported not being able to attend baby groups or clubs due to restricted mobility, and some described this as having a negative impact on their support network.

'Day to day things ... I can't sit down on the floor even with cushions, so I can't sit down on the floor and play with my daughter, or play games on the floor because I know I'll end up in pain if I do that.' (PI)

All the women reported difficulty with lifting and carrying children, an activity described as unavoidable and had to be done despite pain. Some women were restricted in carrying out basic care tasks for their children, such as dressing and bathing, because of the pain of bending at the waist. Other practical tasks, such as walking to school, were also highlighted as problematic.

Personal care activities were also affected, which was especially so when symptoms were at their most severe. Dressing the lower half of the body was the most common problem, which often required assistance to complete. Some women experienced problems also with bath and toilet transfers. Difficulties with bed transfers, and turning in bed were also reported, and in some cases led to problems with sleeping.

'Shoes are difficult. These are just slip on things. Putting on underwear as well I find difficult, I position the knickers on the floor and step into them and it looks like I'm going to tip myself out of bed, and then up.' (P2)

Domestic tasks too were frequently mentioned as problematic. Shopping was painful due to manoeuvring trollies and lifting heavy bags. Vacuuming was painful for most due to the spinal flexion and rotation motion involved. Food preparation and cooking were identified as activities that could lead to increased pain because of having to stand for extended periods. Although most of the women were employed, they did not report problems associated with work, this may have been due to the sedentary nature of their work, which was often from home or in a local office.

All the participants talked about leisure activities they used to enjoy but could no longer participate in due to pain. Often these were active leisure pursuits, but for some the issue was accessing the venue due to restricted mobility. For most, these leisure activities were viewed as an important feature of their identity and were missed:

'Bike riding, I haven't been on a bike since [my youngest son was born], the thought of going on a bike for any length of time...I'm just not sure how it would go. I hope it would go alright because I really love it and I miss it.' (P3)

\section{Factors restricting participation in activity}

All participants reported experiencing intense, acute, and enduring chronic, pain which was seen as having an effect on their ability to participate in activity, as well as being aggravated during those times when they attempted to do the activity. All participants reported experiencing pain after prolonged periods of sitting. Most women reported that the pain could be managed by limiting the 
amount of time sitting in one position and by keeping mobile. Many participants avoided activities that involved sitting for prolonged periods, such as going to the cinema. Bending at the waist or crouching was also an issue for most and was frequently mentioned.

'[At work] I am sat on a chair all day, which is just as problematic as walking. I try and get up and walk around as much as possible, but that can be quite painful in itself, so yes, nothing's simple.' (P4)

For most, the pain when walking was so intense in the weeks and months after childbirth that they rarely left their home. Using a pushchair for some was not possible as they were walking with crutches, others reported using a pushchair effectively as a walking aid. At the time of interview, mobility was not severely impaired for most of the participants; however, episodes of decreased mobility was perceived as a significant issue as participation in activity was then restricted to some degree compared to their abilities prior to having children.

I'm less active, so when I said that I can walk into town and back, I mean yeah I do, but before I would have walked down into town, then on to a friend's house, then walk to the park, then to town and back home. I don't do that anymore. I drive.' (P3)

All participants also talked of refraining from activities because of their fear of exacerbating symptoms. Some reported fear of tripping when walking in the community and that they had to take great care as a consequence not to fall. Lack of awareness and information also affected participation through feelings of uncertainty as to which activities to continue, which to adapt, and which to avoid completely. In many cases, activity avoidance was encouraged by health professionals without any information as to what was happening to them medically or functionally. Most participants reported having to research themselves as to how to manage their symptoms so as to be more able to participate in activity.

'In terms of daily activities there was no information whatsoever, I was just told to rest.' (P2)

\section{Factors promoting participation in activity}

Most participants were living with partners, who in many instances were seen to provide essential support, both practically and emotionally. It was generally perceived that most partners took on responsibilities with the children that they may not have done otherwise. Some women talked positively about this in terms of how it had led to an increased sense of equality regarding childcare and housework.

'My relationship with my partner is fantastic, I couldn't have found a better bloke [man], he's really lovely, he does so much to make things easier for me, I don't have to ask or feel like I'm putting him out when there's things I can't do.' (P3)

The children themselves were also considered as a supportive factor. All the women expressed positive experiences with their children, which encouraged them to participate in certain activities. This contributed towards the women feeling more positive about their restrictions. In the main, participants were more willing to participate in activities that might cause them pain if the children were also involved. Children provided practical support in some cases, such as collecting items from upstairs, and as a result were becoming more independent with household tasks at an earlier age. Support was also received from extended family members, which was seen as helpful. For one participant who did not have any family support, a personal assistant was funded by social services. 
All participants had taken practical steps to try and overcome symptoms. Self-funded manual therapy treatment was seen by most as crucial to reduce symptoms to a point where they were more able to participate in everyday activities. Most used pain relief medication at times but this was generally considered as undesirable. Many participants took up alternative forms of exercise, such as swimming, to help keep active and fit, which was also perceived to promote participation in other activities in the long term.

'With my second child I saw the osteopath self-funded ... I didn't get away scot free but I could still drive, I could make myself lunch, I just had mobility. It wasn't comfortable, but I wasn't housebound and I wasn't what I would call disabled, which I was the first time. '(P4)

All participants discussed how they had adapted activities to be more able to continue to participate in them to some degree. Some adaptations were subtle, such as online shopping, while others were more imaginative, such as using long-handled reachers to load the washing machine, or using homemade boxes on wheels to move objects around. In cases where it was not possible to participate in the desired activity, alternative pursuits and interests were explored, such as reading, and colouring and playing board games with the children rather than active physical play.

'You start to have a lot of things to hand so that you haven't got to go and get them. In my kitchen, I've got a couple of things that I don't put away because I use them daily, a couple of cups and glasses, all these tiny things make a difference.' (P5)

Practical changes were also made to the environment to facilitate participation by most participants. Changes to the home environment were frequently mentioned by those who experienced pain when bending at the waist, and included the raising of work surfaces, fridges and changing tables to avoid this movement. Most of the women also talked about requiring specific seating at home and at work to minimise pain and promote participation in activities ordinarily carried out when sitting.

\section{Emotional impact of a change in participation}

All participants had times when they felt substantial distress because of the symptoms they experienced. Some women were diagnosed with depression or experienced depressive symptoms. This was often mentioned while talking about restricted mobility and being unable to leave the house when pain was at its most severe. Feelings of isolation were commonly experienced and often connected to limited support networks. The lack of awareness of the condition also led to the women feeling misunderstood and frustrated. All participants experienced these feelings, which were compounded by not being able to participate in activities that were important to them and as they would like to.

'There were times I cried and times I threw things in pure frustration at not being able to do the simplest things.' $(P 2)$

Participants had developed a change in how they saw themselves. Many women felt they were not living up to their own expectations of being a mother through limitations in terms of both playful and practical activities with and for their children. Because of their inability to complete certain activities and the restrictions placed upon them by pain, some women perceived themselves as disabled. Becoming dependent on others was also described as difficult to accept by many, and some felt as though they had become a burden on others. Most women talked also about having to accept a new body that was more restricted than that they had before childbirth.

'It's just learning to pace myself really and learning that my body can't do what it used to do, which is pretty horrible when you're in your early thirties.' (P3) 


\section{Discussion}

The aim of this study was to explore the occupational difficulties that are experienced by women with pelvic girdle pain after childbirth, and acquire an understanding of how they have adapted to participate in activity. The findings suggest that women with this condition experience substantial occupational disruption, with symptoms affecting a broad range of activities but especially so in relation to parenting responsibilities.

Participating in play with their child on the floor and active physical play were most affected, consistent with occupational issues faced by mothers with other pain-related conditions (Poole et al, 2009). Play activities between a mother and a child are a typical example of co-occupation because this involves shared physicality, emotionality and intentionality (Pickens and Pizur-Barnekow, 2009). The findings in this study suggests that difficulty for mothers to play with their child reduces opportunities to engage in co-occupation between mother and child, and this may have implications for family wellbeing. However, all the women adapted to this issue by participating in less active cooccupations such as reading and drawing.

Consistent with the findings of Engeset et al (2014), other roles were also affected including that of being a partner and professional. Engeset et al (2014) carried out a hermeneutic phenomenological study interviewing five women all living with partners, whereas this study included a single parent. In Engeset and colleagues' (2014) study, questions were validated via pilot interviews, whereas this study used semi-structured interviews that encouraged open discussion, thereby allowing participants to raise the points that were important to them. Family life and the mothering role of participants were evident in both studies, what was limited, however, were issues relating to intimacy and sexual activity.

Although, the findings in the current study highlight changes in particular to the mothering role, the role of being a worker or a professional appeared to be minimally affected. This is in contrast to previous studies where the impact of pelvic girdle pain on work-based activities is prominent (Elden et al, 2013; Persson et al, 2013). Persson and colleagues' (2013) grounded theory study interviewed nine participants and provides a useful conceptual model highlighting the consequences of pelvic girdle pain. The current study, with a smaller number of participants, allowed for open discussion resulting in findings that might help practitioners better understand how women with pelvic girdle pain cope. For example, the majority of women in the current study were employed, and their views generally were that they were fortunate to have employment that was largely unaffected by their condition because of the sedentary nature of their work, as well as the workplace environment. The absence of work-based occupational issues, as seen in previous studies, strengthens the suggestion that problems may largely be environmental.

The findings also showed personal and activities of daily living to be affected. An inability to fulfil basic needs such as washing, cooking and sleeping is reported to reduce women's ability to cope with physical and emotional stressors, such as those experienced with pelvic girdle pain (Negron et al, 2013). Equipment provision is often used as an intervention to overcome occupational issues such as bed and toilet transfers (Sainty et al, 2009). However, participants in this study appeared to experience symptoms that are subtler and where traditional equipment may not be the best solution in busy shared family households with young children. Despite this, milder symptoms of pelvic girdle pain can present their own challenges through impacting on activities in an invisible way, with less support available (Dow et al, 2012). There may, therefore, be potential for skilled occupational therapy intervention to grade and adapt activities with women living with pelvic girdle pain.

According to Schell et al (2013) leisure activities are integral to personal identity. Women in this study appeared to have substantially reduced their participation in active leisure pursuits, such as 
motorcycling or skiing, previously regarded as important to personal identity before childbirth. The transition to motherhood may however be accompanied by a reduction in some of these leisure activities in any case due to meeting the needs of a child and going through a process of reforming identity (Laney et al, 2015). The findings suggest there is likely to be an increased sense of loss if leisure activities are perceived to be unobtainable because of ongoing pain rather than parental responsibilities towards a child.

Restricted mobility also had an effect on personal identity for the women who previously saw themselves as active or spontaneous. The majority of the women reflected on this changed perception of themselves and talked about acceptance of their current situation and their new body. Perception of a more restricted body was not viewed as temporary by participants but long-term, with some reporting problems up to 9 years post-childbirth. This suggests the consequences of longterm pelvic girdle pain goes beyond the period of 2 years previously considered by Vleeming et al (2008).

Gross motor movement relating to standing, walking, sitting and bending at the waist were reported as actions that led to pain, limiting participation in activity. The European guidelines for the diagnosis and treatment of pelvic girdle pain state that the "endurance capacity for standing, walking and sitting is diminished' for women with this condition (Vleeming et al, 2008). Although bending at the waist is not mentioned in these guidelines, it seems that participants in this study experienced difficulty with this movement, resulting in a negative impact on their ability to participate in daily activities. Changes to the environment consisted mainly of raising work surfaces to avoid the need for spinal forward flexion. These environmental modifications were self-initiated and seen as a way of 'muddling through'. An unintended consequence, however, was pain experienced when lifting children up to raised surfaces, but this was generally seen as preferable over prolonged periods of bending or crouching.

According to Darlow et al (2013), health professionals have a considerable and long-lasting effect on the beliefs of people experiencing low-back pain. This study found that the women were commonly advised to take pain-relief medication and rest, which arguably could lead to activity avoidance and further disability. This issue has previously been attributed to society's normalising of chronic pelvic girdle pain in women, especially after childbirth (Grace and MacBride-Stewart, 2007). Others argue that raising awareness and challenging the notion of pain as being a normal part of childbirth could reduce the negative impact of long-term pelvic girdle pain (Fishburn and Cooper, 2015).

Physiotherapy and osteopathy primarily deliver self-management exercises, which may not be effective when the pelvis is misaligned (Bradbury et al, 2013). A variety of evidence-based rehabilitation programmes are available, including stabilising exercises and manual therapy (Buyruk et al, 1999; Damen et al, 2001; Kanakaris et al, 2011). Treatment that offers mobilisation and manipulation for rapid pain relief and functional improvement, followed by a programme of maintenance exercises, have been seen as beneficial (Bradbury et al, 2013). Women in this study felt that treatment from a physiotherapist or osteopath was the best way to reduce symptoms, but costs could be a barrier.

Support from family and others was seen as beneficial by the women, which helped increase participation in activity. It appears that informal support from family and friends can increase maternal parental self-efficacy and decrease post-natal depression in first time mothers (LeahyWarren et al, 2012). Wuytack et al (2015b) highlight the importance of postpartum follow-up care for women with pelvic girdle pain. They found that women felt ignored by health professionals and sought advice by talking to others, but that many felt uncertain as to what they should do to alleviate pain. 
Much of the literature relating to pelvic girdle pain to date has recruited married or cohabiting participants, who often receive support from their partner (Elden et al, 2013; Persson et al, 2013; Engeset et al, 2014). In this study, only one participant was a single mother with no partner or family support. Her experience highlights the possibility of social services support in such circumstances. However, this may not be available to single mothers with less severe symptoms, or those seeking educational or preventative support. The experience of participants in this study with or without family support suggests that occupational therapy intervention might be beneficial in relation to grading and adapting activities, and could be incorporated into maternal care, as recommended previously by Slootjes et al (2015).

The findings of this study highlights the emotional impact of living with pelvic girdle pain, which it seems can also restrict activity participation - a notion that can seem controversial or dismissive by those experiencing it (Dow et al, 2012). The fear of pain can be as disabling as the pain itself, as it appears there is an association between pain-related fear and disability (Zale et al, 2013). Selfefficacy and self-belief in being able to execute particular tasks is a theme that runs through pain literature (Snelgrove and Liossi, 2013). The women in this study described many activities that they commonly avoid or have concerns about participating in because they are afraid that this will result in pain. This may be resulting from the inability to differentiate between activities that will cause pain and activities that will cause further harm. Consistent with previous literature, clearer information as to which activities are safe to participate in despite pain could increase self-efficacy in women living with pelvic girdle pain (Wuytack et al, 2015a).

Similar to other conditions, pelvic girdle pain impacts emotionally as well as physically. The experience of negative emotions by participants were often expressed in relation to the management of everyday activities. According to Dow et al (2012) personal narratives of frustration in relation to chronic pain suggests that often the source is the perceived impact of pain on everyday activities, especially those that cause roles or identity to be disrupted. This fits with both the findings from this study and previous research relating to pelvic girdle pain after childbirth (Engeset et al, 2014). The experience of personal frustration from the participants appears to stem from a general perception of being misunderstood by health professionals. It could be argued that increased recognition and understanding of symptoms relating to pelvic girdle pain and access to treatment to alleviate pain to enhance participation in activity may improve wellbeing and quality of life for these women.

\section{Study limitations and future research}

The authors do not claim to have carried out a study that fully adheres to hermeneutic theory but hope the findings will inspire researchers to explore this phenomenon further, possibly via a hermeneutic phenomenological method. The findings encourage consideration as to ways to improve quality of life in particular, and further research in this area is recommended. It may also be beneficial for future research to interview single mothers only, or those without family support. The authors recognise too that a small number of women were interviewed and the findings are not generalizable; however, the study may inform practitioners as they reflect on their own practice and ways in which to work with women who experience pelvic girdle pain.

\section{Conclusions}

This study adds to the literature in an area of practice with limited evidence to inform practitioners. The findings suggest that there is an interplay between physical and emotional factors that can restrict participation across a broad range of activities. Support from family and friends, as well as practical changes, were identified as factors that can promote participation. Frustration and a change in perception of the self were described as emotional consequences of living with this condition. It appears that there is potential for occupational therapy to benefit the lives of mothers living with pain 
conditions such as pelvic girdle pain. Adapting activities and the environment were described as strategies for continued participation, and this might be beneficial if introduced before symptoms become long-term. This study therefore illuminates the experience for women living with pelvic girdle pain and may inform practitioners who work in this area of practice.

\section{Declaration of interest}

The authors report no conflicts of interest.

\section{References}

Albert H, Godskesen M, Westergaard J. Prognosis in four syndromes of pregnancy-related pelvic pain. Acta Obstet Gynecol Scand. 2001;80:505-511.

Aldabe D, Milosavljevic S, Bussey MD. 2012 Is pregnancy related pelvic girdle pain associated with altered kinematic, kinetic and motor control of the pelvis? A systematic review. Eur Spine J 21(9): 1777-1787 [PMC][10.1007/s00586-012-2401-1] [22718046]

Bradbury KJ, Bishop FL, Yardley L et al (2013) Patients' appraisals of public and private healthcare: A qualitative study of physiotherapy and osteopathy. J Health Psychol 18(10): 1-12

Braun V, Clarke V (2006) Using thematic analysis in psychology. Qual Res Psychol 3(2); 77-101 [CrossRef][10.1191/1478088706qp063oa]

Brinkmann S, Kvale S (2015) Interviews: Learning the Craft of Qualitative Research Interviewing. $3^{\text {rd }}$ ed. Sage, London

Buyruk HM, Stam HJ, Snijders CJ, Laméris JS, Holland WP, Stijnen TH (1999) Measurement of sacroiliac joint stiffness in peripartum pelvic pain patients with Doppler imaging of vibrations (DIV). Eur J Obstet Gynecol Reprod Biol 83(2): 159-63 [PMC][10391526]

Clancy, M (2013) Is reflexivity the key to minimising problems of interpretation in phenomenological research? Nurse Res 20(6): 12-16 [PMC][23909106]

Crotty M (1998) The foundations of social research: meaning and perspectives in the research process. Sage, London

Damen L, Buyruk HM, Güler-Uysal F, Lotgering FK, Snijders CJ, Stam HJ (2001) Pelvic pain during pregnancy is associated with asymmetric laxity of the sacroiliac joints. Acta Obstet Gynecol Scand 80(11): 1019-24 [PMC][11703199]

Darlow B, Dowell A, Baxter GD et al (2013) The enduring impact of what clinicians say to people with low back pain. Ann Fam Med 11(6): 527-534 [PMC][10.1370/afm.1518] [24218376]

Dow CM., Roche PA, Ziebland S (2012) Talk of frustration in the narratives of people with chronic pain. Chronic Illn 8(3): 176-191 [PMC][10.1177/1742395312443692] [22473060]

Elden H, Lundgren I, Robertson E (2013) Life's pregnant pause of pain: pregnant women's experiences of pelvic girdle pain related to daily life: a Swedish interview study. Sex Reprod Healthc 4(1): 29-34 [CrossRef][10.1016/j.srhc.2012.11.003] 
Engeset J, Stuge B, Fegran L (2014) Pelvic girdle pain affects the whole life - a qualitative interview study in Norway on women's experiences with pelvic girdle pain after delivery. BMC Res Notes 7(1):686 [PMC][10.1186/1756-0500-7-686] [25277975][Mismatch]

Finlay L (2011) Phenomenology for therapists: researching the lived world. Wiley-Blackwell, Chichester

Finlay L, Ballinger C (2006) Qualitative research for allied health professionals: challenging choices. John Wiley \& Sons Ltd, Chichester

Fishburn S, Cooper T (2015) Pelvic girdle pain: Are we missing opportunities to make this a problem of the past? Br J Midwifery 23(11): 774-778 [CrossRef][10.12968/bjom.2015.23.11.774]

Fusch PI, Ness LR (2015) Are we there yet? Data saturation in qualitative research. The Qualitative Report 20(9): 1408-1416

Gadamer HG (1989) Truth and method. $2^{\text {nd }}$ ed. Crossroad, New York

Grace VM, MacBride-Stewart S (2007) 'Women get this': gendered meanings of chronic pelvic pain. Health 11(1): 47-67 [PMC][10.1177/1363459307070803] [17158831][Mismatch]

Kanakaris NK, Roberts CS, Giannoudis PV (2011) Pregnancy-related pelvic girdle pain: an update. BMC Med 9(1): 1-15 [PMC][10.1186/1741-7015-9-15] [21324134]

Laney EK, Hall MEL, Anderson TL et al (2015) Becoming a mother: The influence of motherhood on women's identity development. Identity 15(2): 126-145

[CrossRef][10.1080/15283488.2015.1023440]

Leahy-Warren P, McCarthy G, Corcoran P (2012) First-time mothers: social support, maternal parental self-efficacy and postnatal depression. J Clin Nurs 21(3-4): 388-397

[CrossRef][10.1111/j.1365-2702.2011.03701.x]

Mackenzie J, Murray E, Lusher J (2018) Women's experiences of pregnancy related pelvic girdle pain: a sysyemayic review. Midwifery 56: 102-111 [PMC][10.1016/j.midw.2017.10.011] [29096278][Mismatch]

McCaffrey G, Raffin-Bouchal S, Moules NJ (2012) Hermeneutics as research approach: a reappraisal. Int J Qual Methods 11(3): 214-229 [CrossRef][10.1177/160940691201100303]

National Institute for Health and Care Excellence (2006) Postnatal care up to 8 weeks after birth. London (UK): National Institute for Health and Care Excellence

Negron R, Martin A, Almog M et al (2013) Social support during the postpartum period: mothers' views on needs, expectations, and mobilization of support. Matern Child Health J 17(4): 616-623 [PMC][10.1007/s10995-012-1037-4] [22581378][Mismatch]

Pelvic Obstetric and Gynaecological Physiotherapy (2015) Pregnancy-related pelvic girdle pain: guidance for health professionals. http://pogp.csp.org.uk/publications/pregnancy-related-pelvicgirdle-pain-pgp-health-professionals (accessed 31October 2017) 
Persson M, Winkvist A, Dahlgren L et al (2013) "Struggling with daily life and enduring pain": a qualitative study of the experiences of pregnant women living with pelvic girdle pain. BMC Pregnancy Childbirth 13(111): 2-9[Mismatch]

Pickens ND, Pizur-Barnekow K (2009) Co-occupation: Extending the dialogue. Journal of Occupational Science 16(3): 151-156 [CrossRef][10.1080/14427591.2009.9686656]

Poole JL, Willer K, Mendelson C (2009) Occupation of motherhood: challenges for mothers with scleroderma. Am Journal Occup Ther 63(2): 214-219 [PMC][19432060]

Sainty M, Lambkin C, Maile L (2009) 'I feel so much safer': unravelling community equipment outcomes. Br J Occup Ther 72(11): 499-506 [CrossRef][10.4276/030802209X12577616538717]

Schell BAB, Gillen G, Scaffa ME et al (2013) Willard \& Spackman's occupational therapy. 3rd ed. Lippincott Williams \& Wilkins, Philadelphia

Slootjes H, McKinstry C, Kenny A (2015) Maternal role transition: Why new mothers need occupational therapists. Aust Occup Ther J 63(2): 130-133 [PMC][10.1111/1440-1630.12225] [26450767][Mismatch]

Snelgrove S, Liossi C (2013) Living with chronic low back pain: a metasynthesis of qualitative research. Chronic illn 9(4): 283-301 [PMC][10.1177/1742395313476901] [23585633]

Vermani E, Mittal R, Weeks A (2010) Pelvic girdle pain and low back pain in pregnancy: a review. Pain Pract 10(1): 60-71 [PMC][10.1111/j.1533-2500.2009.00327.x] [19863747]

Vleeming A, Albert HB, Östgaard HC et al (2008) European guidelines for the diagnosis and treatment of pelvic girdle pain. Eur Spine J 17(6): 794-819 [PMC][10.1007/s00586-008-0602-4] [18259783][Mismatch]

Wuytack F, Curtis E, Begley C (2015a) Experiences of first-time mothers with persistent pelvic girdle pain after childbirth: descriptive qualitative study. Physical Therapy 95(10): 1354-1364 [CrossRef][10.2522/ptj.20150088][Mismatch]

Wuytack F, Curtis E, Begley C (2015b) The health-seeking behaviours of first-time mothers with persistent pelvic girdle pain after childbirth in Ireland: A descriptive qualitative study. Midwifery 31(11): 1104-1109 [CrossRef][10.1016/j.midw.2015.07.009][Mismatch]

Yerxa EJ (1990) An introduction to occupational science, a foundation for occupational therapy in the 21st century. Occup Ther Health Care. 6(4): 1-17 [PMC][10.1080/J003v06n04_04] [23931133]

Zale EL, Lange KL, Fields SA (2013) The relation between pain-related fear and disability: a metaanalysis. Journal of Pain 14(10): 1019-1030 [PMC][10.1016/j.jpain.2013.05.005] [23850095] 